\title{
Metabolic syndrome is associated with a poor outcome in patients affected by outflow tract premature ventricular contractions treated by catheter ablation
}

\author{
Celestino Sardu', Giovanni Carreras², Spyridon Katsanos ${ }^{3}$, Vasileios Kamperidis ${ }^{4}$, Maria Caterina Pace ${ }^{5}$, \\ Maria Beatrice Passavanti ${ }^{5}$, Ilaria Fava ${ }^{1}$, Pasquale Paolisso ${ }^{1}$, Gorizio Pieretti ${ }^{6}$, Giovanni Francesco Nicoletti ${ }^{6}$, \\ Gaetano Santulli', Giuseppe Paolisso ${ }^{1}$ and Raffaele Marfella ${ }^{1,8^{*}}$
}

\begin{abstract}
Background: The purpose of this study was to investigate the impact of metabolic syndrome (MS) on outcome of catheter ablation (CA) for treatment of frequent premature ventricular contraction beats (PVCs) originating from right ventricular outflow tract (RVOT), left ventricular outflow tract (LVOT) or coronary cusps (CUSPs), in patients with normal ventricular systolic function and absence of cardiac structural disease.

Methods: In this multicentre prospective study we evaluated 90 patients with frequent PVCs originating from RVOT $(n=68)$, LVOT $(n=19)$ or CUSPs $(n=3)$, treated with CA. According to baseline diagnosis they were divided in patients with MS $(n=24)$ or without MS $(n=66)$. The study endpoint was a composite of recurrence of acute or delayed outflow tract ventricular arrhythmia: acute spontaneous or inducible outflow tract ventricular arrhythmia recurrence or recurrence of outflow tract PVCs in holter monitoring at follow up.

Results: Patients with MS compared to patients without MS showed a higher acute post-procedural recurrence of outflow tract PVCs $(n=8,66.6 \%$, vs. $n=6,9.0 \%, p=0.005)$. At a mean follow up of 35 (17-43) months survival free of recurrence of outflow tract PVCS was lower in patients with baseline MS compared to patients without MS diagnosis (log-rank test, $p<0.001$ ). In cox regression analysis, only MS was independently associated with study endpoint $(\mathrm{HR}=9.655,95 \% \mathrm{Cl} 3.000-31.0 .68, \mathrm{p}<0.001)$.
\end{abstract}

Conclusions: MS is associated with a higher recurrence rate of outflow tract PVCs after CA in patients without structural heart disease.

\section{Background}

According to the Third report of the National Cholesterol Education Program (NCEP) expert panel on detection, evaluation, and treatment of high blood cholesterol in adults (Adult Treatment Panel III) [1], metabolic syndrome (MS) is a clinical condition defined by evidence of several risk factors including obesity, hypertension, diabetes, and dyslipidaemia and it is related to a pro inflammatory and pro thrombotic state [2]. MS identifies

\footnotetext{
* Correspondence: raffaele.marfella@unina2.it

'Department of Medical, Surgical, Neurological, Metabolic and Geriatric

Sciences, Second University of Naples, Naples, Italy

${ }^{8}$ Current address: Piazza Miraglia, 2, Napoli 80138, Italy

Full list of author information is available at the end of the article
}

patients at increased risk for cardiovascular disease (CVD), type 2 diabetes mellitus, and all-cause mortality [3-5], and approximately one-fifth of the adult U.S. population would be classified as having MS with an upward trend in abdominal obesity and insulin resistance [6]. Patients with uncomplicated MS have a greater dispersion of ventricular repolarization time and augmented maximal and minimal QTc [7], with increased possibility of ventricular re-entry circuits [8-10] and increased frequency of premature ventricular contractions (PVCs) compared to healthy controls [11,12]. Ventricular arrhythmias and PVCs originating from right ventricular or left ventricular outflow tract (RVOT, LVOT) and coronary cusps (CUSPs), 
characterized by inferior axis, precordial left bundle branch block (LBBB) morphology and V3 or V4 precordial transition on surface electrocardiogram (ECG) are often benign and not related to structural heart disease [13]. These arrhythmias are caused by triggered activity due to cyclic adenosine monophosphate (cAMP)- mediated calcium-dependent delayed after depolarizations, and related to a arrhythmogenic cell focus firing and triggering induction mechanisms like catecholamine infusion, and are responsible to adenosine as well as verapamil administration [14]. Recent data evidenced the role of oxidative stress in initiating cardiovascular consequences in MS. The enhanced oxidative stress exacerbates inflammation, which in turn further exacerbates oxidative stress, generating a vicious cycle, leading to sympathetic over activity and eventually ventricular arrhythmias [15]. Thus, sympathetic over activity state related to MS may represent an irritating and triggering mechanism on these outflow tract PVCs. According to guidelines there is a class I indication for ventricular arrhythmias catheter ablation (CA) in patients at low risk for sudden death, in absence of structural heart disease [16] and authors have observed beneficial effects on left and right ventricular function in patients with PVCs and preserved left ventricular ejection fraction [17]. There are no evidences about catheter ablation (CA) outcomes in MS patients affected by idiopathic or benign PVCs. In this context, our study hypothesis is to examine the impact of MS on CA outcome of idiopathic PVCs in patients with preserved ventricular systolic function and absence of cardiac structural disease.

\section{Methods}

\section{Patient population}

In this multicentre prospective study we evaluated, from September 2010 to December 2013, all consecutive patients $(\mathrm{n}=90)$ who were treated by CA of idiopathic focal PVCs, originating from the RVOT $(n=68)$, LVOT $(n=19)$ or CUSPs $(n=3)$, at Federico II university of Naples (Naples, Italy), S. Maria di Loreto Mare Hospital (Naples, Italy), and S. Maria Terni Hospital (Terni, Italy). Inclusion criteria were: 1) presence of RVOT, LVOT or CUSPs origin PVCs, 2) all patients have discontinued the anti-arrhythmic drugs (AADs) 4-5 half live before to perform the ablation, 3) absence of any structural heart disease, normal ventricular systolic function, 4) normal thyroid function and electrolyte values, 5) normal renal function, 6) absence of neoplastic disease. For every patient to rule out structural heart disease, a comprehensive clinical evaluation was performed, which included medical history, 12-lead electrocardiogram (ECG), and two dimensional transthoracic echocardiography. If exclusion of structural heart disease was deemed necessary, exercise testing, coronary angiography, cardiac multidetector computed tomography (CMCT), and/or nuclear imaging were performed. Prior to CA, 12-lead ECG recording of the PVCs and 24-hour Holter registration were acquired for all patients, and the evidence of more than three consecutive monomorphic PVCs beats were classified as ventricular tachycardia (VT). Baseline fasting blood samples were obtained from all patients for the measurement of blood glucose, lipid profile, and C Reactive Protein (CRP) (Elecsys 2010, Roche Diagnostics). The CRP cut off value was set at $0.9 \mathrm{mg} / \mathrm{dl}$, with values below and above this cut off considered normal and high, respectively. Nitrotyrosine plasma concentration was assayed by enzyme-linked immunosorbent assay. Nitrotyrosine was determined because this modified amino acid is a product of free-radical $\left(\mathrm{O}^{2-}\right)$ interaction with nitric oxide (NO). The interaction of $\mathrm{O}^{2-}$ with $\mathrm{NO}$ leads to a rapid inactivation of $\mathrm{NO}$ and to a production of the potent oxidant peroxynitrite. Detection of nitrotyrosine is strongly suggestive of increased generation of peroxynitrite [18]. Patients were diagnosed with MS if they had at least 3 of these risk factors, according to Adult Treatment Panel III MS definition [1]: waist circumference $>102 \mathrm{~cm}$ in men and $88 \mathrm{~cm}$ in women, high-density lipoprotein $<40 \mathrm{mg} / \mathrm{dl}$ in men and $<50 \mathrm{mg} / \mathrm{dl}$ in women and serum triglycerides $>150 \mathrm{mg} / \mathrm{dl}$, blood pressure $>130 / 85 \mathrm{~mm} \mathrm{Hg}$ or on antihypertensive medication, fasting blood glucose $>100 \mathrm{mg} / \mathrm{dl}$ or on antidiabetic medication. According to authors [19] if body mass index is over $30 \mathrm{~kg} / \mathrm{m} 2$, central obesity can be assumed and waist circumference does not need to be measured. The study was approved by institutional review boards and ethics committees at Federico II university of Naples (Naples, Italy), S. Maria di Loreto Mare Hospital (Naples, Italy), and S. Maria Terni Hospital (Terni, Italy). All patients provided written informed consent.

\section{Ablation procedure}

In discontinuation of AADs 4-5 half live before performing the electrophysiological study and catheter ablation, and in conscious sedation by transfemoral right femoral vein access a quadripolar diagnostic catheter $4 \mathrm{~mm}$ fixed curve (Biosense Inc., Diamond Bar, CA; St. Jude Medical, Inc., St. Paul, MN, USA ) has been placed first in right ventricle apex and subsequently in RVOT for reference and pacing manoeuvres. In the presence of clinical PVCs, activation mapping was performed using a 4-mm tip ablation catheter, placed by transfemoral right femoral vein (RVOT) or artery (LVOT and CUSPs) and pace mapping was performed in addition to activation mapping to identify the PVC focus during sinus rhythm. In patients without spontaneous PVCs, programmed ventricular stimulation was performed from the right ventricular (RV) apex and RVOT at three drive cycle lengths with up to three extra stimuli and incremental burst pacing at a cycle length up to $250 \mathrm{~ms}$, at baseline and during isoproterenol infusion. All endocavitary signals 
have been registered, filtered and analysed by an expert cardiologist by a polygraph (Lab System Pro, Bard Electrophysiology, Lowell, MA, USA). In all patients, a three-dimensional non-fluoroscopic imaging and mapping system (CartoXP and Carto 3, Biosense Inc., Diamond Bar, CA; Ensite Navx, St. Jude Medical, Inc., St. Paul, MN, USA) was used for catheter localization and activation mapping. Radiofrequency energy was delivered with a 4-mm-tip non irrigated catheter (Biosense Inc., Diamond Bar, CA, or St. Jude Medical, Inc., St. Paul, MN, USA ) with a target temperature of $60^{\circ} \mathrm{C}$ at a power of $35 \mathrm{~W}$ or with a 4-mm-tip irrigated ablation catheter (Biosense Inc., Diamond Bar, CA or St. Jude Medical, Inc., St. Paul, MN, USA) in temperaturecontrolled mode with a target temperature of $45^{\circ} \mathrm{C}$ at a power of $30 \mathrm{~W}$. If the PVCs were abolished within $20 \mathrm{sec}-$ onds, the energy application was continued for 60 seconds, while if PVCs were still present after 25-30 seconds, the energy application was terminated, and mapping was continued to find an optimal target site. After catheter ablation programmed ventricular stimulation performed from the right ventricular (RV) apex and RVOT at three drive cycle lengths with up to three extra stimuli and incremental burst pacing at a cycle length up to $250 \mathrm{~ms}$, at baseline and during isoproterenol infusion. On and off isoproterenol infusion were utilized to confirm the effectiveness of CA in all patients. Acute success was defined as the absence of out flow tract PVCs with similar morphology during a $30 \mathrm{mi}-$ nutes observation period after CA, and in absence of clinical PVCs during programmed ventricular stimulation.

\section{End point}

The end point was considered a composite of 1 . acute absence of spontaneous or inducible outflow tract PVCs (OT-PVCs), with isoproterenol infusion or bursts pacing from right ventricular apex and RVOT for $30 \mathrm{mi}-$ nutes following the last radiofrequency lesion, and 2 . delayed and late recurrence of OT-PVCs at a rate of $\leq$ 300 beats per day documented by $24 \mathrm{~h}$ Holter monitoring at scheduled follow up visits.

\section{Follow up}

All patients were followed in the outpatient department within 2 weeks, and thereafter at monthly intervals, during which physical examination and 12-lead ECG were conducted. Routine 12-lead Holter monitoring was performed at the $1^{\text {st }}, 3^{\text {rd }}, 6^{\text {th }}$ and $12^{\text {th }}$ month and echocardiography was performed at the $3^{\text {rd }}$ and $6^{\text {th }}$ month floow-up. Whenever patients had symptoms of palpitations, dizziness, or syncope during follow-up, they were advised to contact their doctors immediately for evaluation of vital signs, 12-lead ECG, and12-lead 24 hour Holter monitoring. All AADs were discontinued after successful ablation procedure.

\section{Statistical analysis}

Statistical analyses were carried out with a package of SPSS software version 20 (SPSS Inc., Chicago, IL, USA). Kolmogorov-Smirnov test was used to check the Gaussian distribution of continuous variables. Continuous variables were presented as mean \pm standard deviation if normally distributed or as median (interquartile range), otherwise. Categorical variables were presented as number and frequencies. Patients were dichotomized according baseline diagnoses of MS. The Student's t-test or Mann-Whitney test were used to compare continuous variables as appropriate. Additionally, $\chi^{2}$ test or Fisher's exact test, were used to compare categorical variables, as recommended. All long term survival analyses were calculated from the date of the procedure. The Log-rank test for time-to-event data with respect to recurrence of study endpoint was used for statistical comparison between patients with and patients without MS. Univariate and multivariate Cox proportional hazards models were performed to identify independent associates of the endpoint. The estimated hazard ratios and the $95 \%$ confidence intervals were computed. Only univariate variables with $\mathrm{p}<0.05$ were included in the multivariate model. For multivariate modelling, BMI > $30 \mathrm{~kg} / \mathrm{m}^{2}$, hypertension, dyslipidaemia and diabetes were omitted due to collinearity with MS. A two-sided $\mathrm{p}<0.05$ was considered statistically significant.

\section{Results and discussion}

The mean age of the population was $40 \pm 16$ years (male 53.3\%). By definition, patients with MS had higher BMI, and higher rates of dyslipidaemia, hypertension, and diabetes (Table 1). Creatinine, Nitrotyrosine and C Reactive Protein (CRP) were also higher in the MS group (1.1 $(1.0-1.2) \mathrm{mg} / \mathrm{dl}$ vs $1.0(0.9-1.0) \mathrm{mg} / \mathrm{dl}, \mathrm{p}=0.004,0.42 \pm$ $0.03 \mu \mathrm{mol} / \mathrm{L} \mathrm{v} / \mathrm{s} \quad 0.27 \pm 0.02 \mu \mathrm{mol} / \mathrm{L}, \mathrm{p}<0.001$ and 5.3 (3.2-7.2) $\mathrm{mg} / \mathrm{dl}$, vs. $2.7(1.7-4.0) \mathrm{mg} / \mathrm{dl}, \mathrm{p}<0.001$, respectively). Values of oxidative stress marker (nitrotyrosine) levels were higher in MS group (Table 1). Patients with MS compared to patients without MS were more commonly treated with angiotensin-converting enzyme inhibitors and angiotensin receptor blockers (ACE/ARB blockers), betablockers and lipid-lowering therapy (Table 1). Interestingly, patients with MS as opposed to patients without MS had higher baseline heart rate (HR) $(72 \pm 11$ beats/min vs. $65 \pm$ 10 beats $/ \mathrm{min}, \mathrm{p}=0.015$ ), higher PVCs burden at baseline (7263 \pm 1766 beats/day vs $7263 \pm 1766$ beats/day, $p=0.042$ ) and longer CA procedural time $(163.9 \pm 39.1 \mathrm{~min}$ vs. $141 \pm$ 24 min, $\mathrm{p}=0.002)$ (Table 2).

\section{Study endpoint}

There were 14 cases of acute PVCs recurrence (15,5\%). The rate of spontaneous or inducible PVCs with isoproterenol infusion and bursts pacing from right ventricular apex and RVOT for 30 minutes following the 
Table 1 Baseline population characteristics

\begin{tabular}{|c|c|c|c|c|}
\hline Variable & $\begin{array}{l}\text { Total population } \\
(\mathrm{n}=90)\end{array}$ & $\begin{array}{l}\text { Patients with MS } \\
(n=24)\end{array}$ & $\begin{array}{l}\text { Patients without MS } \\
(\mathrm{n}=66)\end{array}$ & $p$-value \\
\hline Age (years) & $40 \pm 16$ & $53 \pm 12$ & $35 \pm 15$ & $<0.001$ \\
\hline Male n(\%) & $48(53.3 \%)$ & $10(41.6 \%)$ & $38(57.5 \%)$ & 0.181 \\
\hline $\mathrm{BMI}\left(\mathrm{kg} / \mathrm{m}^{2}\right)$ & $27.7 \pm 3.3$ & $31.7 \pm 1.2$ & $26.3 \pm 2.6$ & $<0.001$ \\
\hline Dyslipidemia n (\%) & $32(35.6 \%)$ & $22(91.6 \%)$ & $10(15.1 \%)$ & $<0.001$ \\
\hline Hypertension n (\%) & 41 (45.6\%) & $23(95.8 \%)$ & $18(27.2 \%)$ & $<0.001$ \\
\hline Diabetes n (\%) & $10(11.1 \%)$ & $10(41.6 \%)$ & $0(0 \%)$ & $<0.001$ \\
\hline Creatinine (mg/dl) & $1.0(0.9-1.2)$ & $1.1(1.0-1.2)$ & $1(0.9-1.0)$ & 0.004 \\
\hline Nitrotyrosine $(\mu \mathrm{mol} / \mathrm{L})$ & $0.31 \pm 0.07$ & $0.42 \pm 0.03$ & $0.27 \pm 0.02$ & $<0.001$ \\
\hline CRP (mg/dl) & $3.7(1.8-5.3)$ & $5.3(3.2-7.2)$ & $2.7(1.7-4.0)$ & $<0.001$ \\
\hline \multicolumn{5}{|l|}{ PVCs origin site } \\
\hline RVOT n (\%) & $68(75.6 \%)$ & $20(83.3 \%)$ & $48(72.7 \%)$ & 0.791 \\
\hline LVOT n (\%) & 19 (21.1\%) & $3(12.5 \%)$ & $16(24.2)$ & 0.227 \\
\hline CUSPs n (\%) & $3(3.3 \%)$ & $1(4.1 \%)$ & $2(3.0 \%)$ & 0.610 \\
\hline \multicolumn{5}{|l|}{ Echocardiography } \\
\hline LVTDd (mm) & $50.0 \pm 5.5$ & $50.1 \pm 5.3$ & $50.0 \pm 5.5$ & 0.933 \\
\hline LVTSd (mm) & $28.7 \pm 4.6$ & $30.2 \pm 4.3$ & $28.1 \pm 4.6$ & 0.058 \\
\hline LVEF (\%) & $57 \pm 5$ & $57 \pm 3$ & $57 \pm 5$ & 0.982 \\
\hline \multicolumn{5}{|l|}{ Medication } \\
\hline ACEi/ARBs n (\%) & $33(36.7 \%)$ & $21(87.5 \%)$ & $12(18.1 \%)$ & $<0.001$ \\
\hline Beta blockers n (\%) & $16(17.8 \%)$ & $13(54.1 \%)$ & $3(4.5 \%)$ & $<0.001$ \\
\hline Lipid-lowering therapy n (\%) & $29(32 \%)$ & 19 (79.1\%) & $10(15.1 \%)$ & $<0.001$ \\
\hline Class I AADs n (\%) & $16(17.8 \%)$ & $11(45.8 \%)$ & $5(7.5 \%)$ & $<0.001$ \\
\hline Class III AADs n (\%) & $3(3.3 \%)$ & $2(8.3 \%)$ & $1(1.5 \%)$ & 0.172 \\
\hline Class IV AADs n (\%) & $3(3.3 \%)$ & $2(8.3 \%)$ & $1(8.3 \%)$ & 0.172 \\
\hline Follow-up months n (\%) & $39(32-45)$ & $35(24-45)$ & $40(34-45)$ & 0.356 \\
\hline
\end{tabular}

Continuous variables are expressed as mean $\pm S D$ if normally distributed or as median (IQR: 25th percentile, 75th percentile) if not normally distributed, categorical variables are expressed as number (percentage). AADs anti arrhythmic drugs; ACEi/ARBs blockers angiotensin-converting enzyme inhibitors and angiotensin receptor blockers; CRP C-reactive protein; CUSPs aortic cusps; LVEF left ventricle ejection fraction; LVOT left ventricular outflow tract; LVTDd left ventricle end-diastolic diameter; LVTSd left ventricle end-systolic diameter; PVCs premature ventricular contractions; RVOT right ventricular outflow tract.

Table 2 HR, PVCs morphology, PVCs burden and ablation procedure characteristics

\begin{tabular}{lllll}
\hline Variable & General population & $\begin{array}{l}\text { Group 1 (with MS) } \\
(\mathbf{n = 2 4 )}\end{array}$ & $\begin{array}{l}\text { Group 2 (without MS) } \\
(\mathbf{n = 6 6 )}\end{array}$ & $\begin{array}{l}\text { P Value } \\
\text { HR baseline (bpm) }\end{array}$ \\
PVC burden & $67 \pm 10$ & $72 \pm 11$ & $65 \pm 10$ & 0.015 \\
QS wave in DI n (\%) & $7455 \pm 2021$ & $8226 \pm 2407$ & $19(28.7 \%)$ & 0.042 \\
Precordial transition & $23(25.6 \%)$ & $4(16.6 \%)$ & $9(13.6 \%)$ & 0.244 \\
before V4 n (\%) & $11(12.2 \%)$ & $2(8.3 \%)$ & & 0.721 \\
Fluoroscopic time (min) & $22.8 \pm 10.2$ & $22.7 \pm 8.0$ & $20.5 \pm 9.1$ & 0.299 \\
RF time (min) & $6.54 \pm 3.4$ & $7.2 \pm 2.8$ & $6.2 \pm 3.5$ & 0.206 \\
Procedural time (min) & $147.55 \pm 30.8$ & $163.9 \pm 39.1$ & $141 \pm 24$ & 0.002 \\
\hline
\end{tabular}

Variables are expressed as mean \pm SD or median (IQR: 25 th percentile, 75 th percentile) if not normally distributed.

AADs, antiarrhythmic drugs; $\mathrm{HR}$, heart rate in beats for minute (bpm); PVC, premature ventricular beats; QS wave in DI derivation on surface ecg; $R F$, radiofrequency catheter ablation. 
last radiofrequency lesion acute PVC was significantly higher in patients with MS compared to patients without MS ( $n=8,66.6 \%$, vs. $n=6,9.0 \%, p=0.005)$. During a follow up there were, 8 more patients $(8,8 \%)$, evidenced of PVCs at a rate of $>300$ beats per day documented by $24 \mathrm{~h}$ Holter. In total, $22(24.4 \%)$ patients reached the study endpoint (14 patients had acute and 8 patients delayed PVCs). None of the patients died during follow-up.

The Kaplan-Meier curves show survival rates free of the composite study endpoint for patients divided according to baseline diagnosis of MS (Figure 1). The recurrence of acute or delayed PVCs free survival at 12 and 24 months follow up in the MS group were $50 \%$ and $9 \%$ compared with $89 \%$ and $87 \%$ in the group of patients without MS, respectively (log-rank $\mathrm{p}<0.001$ ) (Figure 1 ).

From the univariate Cox proportional hazards analysis, MS (HR $=9.119,95 \% \mathrm{CI}=3.461-24.024, \mathrm{p}<0.001)$, CRP $(\mathrm{HR}=1.25395 \% \mathrm{CI}=1.035-1.516, \mathrm{p}=0.021)$, and procedural time $(\mathrm{HR}=1.015,95 \% \mathrm{CI}=1.004-1.027, \mathrm{p}=0.015)$ were included in the multivariable model (Table 3). Finally, only MS was independently associated with the study endpoint $(\mathrm{HR}=9.119,95 \% \mathrm{CI}=3.461-24.024, \mathrm{p}<$ 0.001) (Table 3).

\section{Complications}

After CA 3 hematoma complications, 1 arteriovenous fistula and 1 case of acute pericardial effusion occurred. During the follow up in the catheter ablation failure group, patients remained under AADs and $14(58,3 \%)$ of them experienced a drug related adverse effect: symptomatic low blood pressure in flecainide treated patients

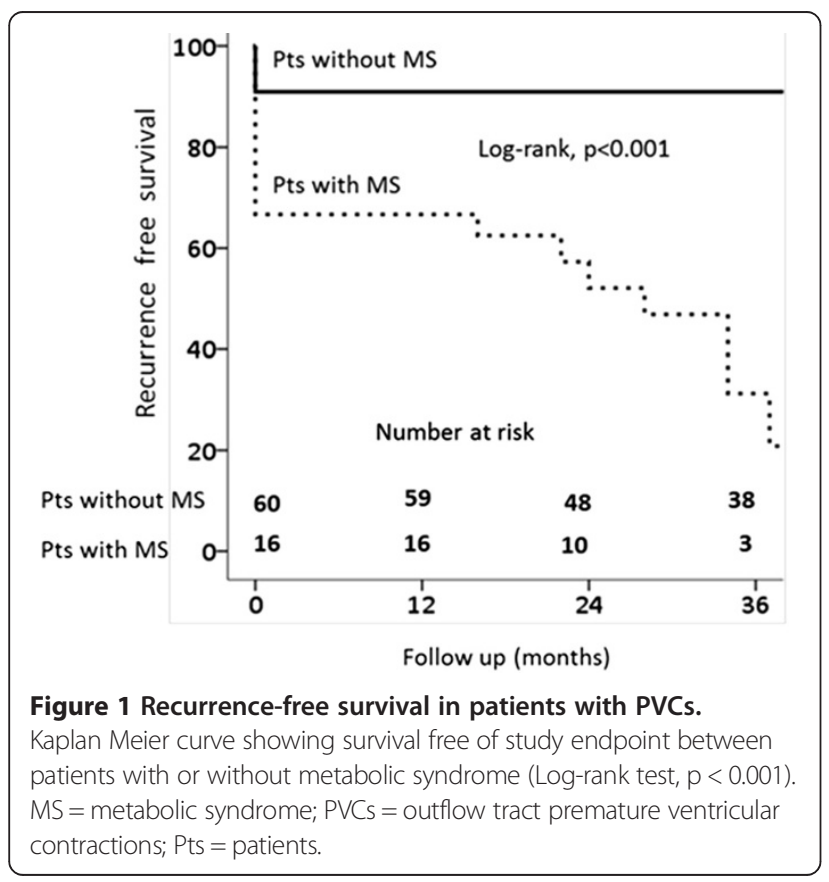

$(\mathrm{n}=5)$, obstructive acute lung disease, hypotension and symptomatic bradycardia in beta blockers treated patients $(\mathrm{n}=7)$, and recurrent headaches and hypotension in propafenone group $(\mathrm{n}=2)$.

In this study we have examined the impact of MS on acute and long term follow up catheter ablation in a population of PVCs patients without evidence of structural heart disease and normal heart function. Our main observations were the following: 1 . in the overall population who had undergone CA for PVCs, MS was associated with significantly higher acute CA failure. 2. MS was an independent prognostic factor of acute and delayed PVCs recurrence after CA.

MS has some direct or indirect influence on ventricular electrophysiology by different action pathways and altering the ionic channels conduction properties. The higher prevalence of obesity, dyslipidaemia, hypertension and diabetes leads MS patients to an augmented oxidative stress and arrhythmogenesis, with abnormalities in sympatho-vagal balance, QT interval and QT dispersion and a fibrotic and adipotic Cardiac Conduction System involvement [7-10].

The obesity, a common risk factor associated with MS [2], can lead to high rates of sudden cardiac death (SCD), before the development of heart disease [20,21], and an increased frequency of premature ventricular contractions compared to healthy controls, unrelated to hypertension or concentric ventricular hypertrophy $[22,23]$.

Elevated plasma free fatty acid level has a stimulatory effect on the sympathetic nervous system [24], with an increased sympathetic and a decreased parasympathetic tone in obese patients [25].

Adipocytokines from epicardial fat significantly decrease delayed rectifier outward currents prolonging action potential duration and facilitating triggered activity with early after depolarizations [9], increasing dispersions of action potential duration and leading to a higher possibility of re-entry circuits [9-11], causing ventricular tachycardia and sudden cardiac death [22]. In our study there is an higher baseline heart rate and PVCs burden in MS than in overall population which may be explained by an abnormal sympatho-vagal balance in MS population, and by a Conduction System involvement with conduction channels alterations and an augmented susceptibility to arrhythmogenesis.

The augmented systemic oxidative stress is associated with cardiac electrical and structural remodelling [26-28], and reactive oxygen species may impair $\mathrm{Na}, \mathrm{K}$, Ca channels and $\mathrm{Na}-\mathrm{Ca}$ exchanger activity, leading to gap junction remodelling, decreasing the action potential amplitude and duration, and increasing the incidence of cardiac arrhythmias in animal models [15]. In fact, oxidative stress results in decreased hERG protein levels, accelerated activation and deactivation of hERG, increased in current amplitude 
Table 3 Multivariate cox regression analysis for parameters associated with study endpoint

\begin{tabular}{|c|c|c|c|c|}
\hline \multirow[t]{2}{*}{ Variable } & \multicolumn{2}{|c|}{ Univariate analysis } & \multicolumn{2}{|c|}{ Multivariate analysis } \\
\hline & HR $(95 \% \mathrm{Cl})$ & p-value & HR $(95 \% \mathrm{Cl})$ & p-value \\
\hline MS & $9.119(3.461-24.024)$ & $<0.001$ & $9.655(3.000-31.068)$ & $<0.001$ \\
\hline Age (years) & $1.023(0.997-1.050)$ & 0.083 & & \\
\hline${ }^{*} \mathrm{BMI} \geq 30\left(\mathrm{~kg} / \mathrm{m}^{2}\right)$ & $8.1(3.0-21.454)$ & $<0.001$ & & \\
\hline Hypertension & $2.656(1.068-6.604)$ & 0.036 & & \\
\hline Dyslipidemia & $3.447(1.417-8.384)$ & 0.006 & & \\
\hline Diabetes & $2.785(1.015-7.638)$ & 0.047 & & \\
\hline Creatinine (mg/dl) & $0.652(0.162-2.616)$ & 0.546 & & \\
\hline${ }^{*}$ Nitrotyrosine $\times 100(\mu \mathrm{mol} / \mathrm{L})$ & $1.136(1.074-1.202)$ & $<0.001$ & $0.64(0.12-3.52)$ & 0.611 \\
\hline CRP $(\mathrm{mg} / \mathrm{dl})$ & $1.253(1.035-1.516)$ & 0.021 & $0.940(0.767-1.151)$ & 0.977 \\
\hline Heart rate baseline (bpm) & $1.011(0.973-1.051)$ & 0.573 & & \\
\hline PVC burden (per 100 beats/24 hours increase) & $1.017(0.997-1.038)$ & 0.096 & & \\
\hline
\end{tabular}

BMI body mass index; CRP C reactive protein; HR Hazard Ratio; PVC premature ventricular contractions.

${ }^{*} \mathrm{MS}, \mathrm{BMI}$ and Nitrotyrosine levels were significantly associated with the study endpoint, $\mathrm{P}<0.001$.

of hERG and hKv1.5, allowing a greater amount of $\mathrm{K}$ ions to flow through these channels in the phase 3 of the action potential, down regulation of Ito (transient outward potassium current) responsible for the rapid repolarization phase, and increased the channel opening probability of Ik1 (inward rectifying channel) [27,28].

The alteration in cardiac oxidative stress, investigated by an higher expression of serum biomarkers like nitrotyrosine and $C$ reactive protein (CRP), leads to alterations in ionic channels conductions properties favouring arrhythmogenic activity in MS population.

At long term these irritative and pro inflammatory stimuli may become pro fibrotic leading to structural fibrotic alterations of the sinoatrial node and throughout the conduction system, the atrioventricular node, atrioventricular bundle and left bundle branch [29]. Added to these fibrotic alterations other structural abnormalities such as localized wall bulging, wall thinning, fatty infiltration, and fibrosis exist in the RVOT, not only in patients with Arrhythmogenic Right Ventricle Cardiomyopathy (ARVC), [30,31] but also in patients with RVOT tachycardia [32].

If these subclinical myocardial structural alterations may be an important factor limiting the efficacy of CA outcome in general population [33], in MS patients with different morphology of PVCs on surface ECG (different precordial transition and q wave in lead I) and PVCs origin focus have shown not different outcomes, observing all PVCs population and separately RVOT, LVOT and CUSPs PVCs.

This may be explained because, in MS patients, the presence of a constellation of risk factors can alter and affect the prognosis also in evidence of a good ablation target, and in our study the only independent predictor of short and long term follow up catheter ablation failure is MS.
In the two groups there is not a difference regarding the fluoroscopic time and the ablation time (RF time), while there is a significant difference related to total procedural time. We can explain these observations than to the modern technologies utilized, because first in all patients we have utilized as described before two different 3D non fluoroscopic mapping system (CartoXP and Carto 3, Biosense Inc., Diamond Bar, CA; Ensite Navx, St. Jude Medical, Inc., St. Paul, MN, USA), that help to record and target more accurately tachycardia origin for ablation than with fluoroscopy alone, and allow catheter positioning without the use of fluoroscopy, reducing fluoroscopy time and radiation dose [34-36], and secondary also for catheter ablation we can consider to have utilized a standardized protocol, using in more time same energy source (radiofrequency) with same target energy (watt), temperature and pulse duration (maximum 60" for every ablation point). On other hand the higher total procedural time observed in MS may be due to technical difficulties related to multiple risk factors present in MS, than can influence the intraoperative management of MS patients prolonging the total procedural time.

The multifactorial risk factors in MS altering oxido/redux balance by a proinflammatory status, lead to an abnormal sympathetic tone and complex alterations in electrophysiological properties from baseline in affected patients.

All these molecular processes connected with MS represent a pro-inflammatory permanent condition triggering the arrhythmogenic cells firing in patients with PVCs not related to cardiac structural disease and without cardiac dysfunction, and leading to an higher tendency and propensity to arrhythmogenicity.

In a recent study [37] authors have shown a worse catheter ablation outcome in MS patients affected by 
atrial fibrillation, highlighting the fact that MS related proinflammatory status can affect ablation outcome.

Until now at our knowledge there are not studies focused on idiopathic PVCs catheter ablation outcome in MS overall general population.

In our study we try to show the impact of MS on patients affected by idiopathic PVCs undergoing catheter ablation therapy, without structural heart diseases and altered cardiac function.

The investigated proinflammatory status and altered sympathetic-vagal tone in MS population may identify at baseline patients with less possibility to respond to CA, also in absence of cardiac structural alterations and cardiac dysfunctions and so apparently not different in this from overall population if selected for $\mathrm{CA}$ of benign and idiopathic PVCs.

These subclinical alterations are not simple to detect with modern technologies, but in current clinical practice we could at last identify and treat step by step all these risk factors implicated in MS, targeting in this way a better control of a complex clinical condition like MS, before to select MS patients candidates to idiopathic PVCs catheter ablation.

In our opinion next clinical question may be to evaluate in a future prospective randomized trial if a more effective and aggressive control of all these risk factors associated with MS may lead to a better ablation outcome.

This treatment before a catheter ablative approach in MS may be more beneficial and influence short term and long term follow up outcome of idiopathic or benign PVCs .

C. S. received an European Society of Cardiology and European Heart Rhythm Association training grant. S. K. received a Hellenic Cardiological Society training grant. V. K. received a European Society of Cardiology training grant, an European Association of Cardiovascular Imaging research grant.

\section{Study limitations}

Several limitations may have influenced our results. First, although periodic 12-lead ECG and 24 hour Holter were performed during the follow-up period, episodes of asymptomatic PVCs or more serious arrhythmias might have been missed in some patients. Second, the study sample size and follow-up duration may have been insufficient to fully characterize the incidence of lethal arrhythmias among study groups. Third, patients were not followed for any status change in their MS component, that may affect and influence long term ablation outcome. Fourth, we did not obtain waist circumference measurement data, which would have illustrated the abdominal obesity status of the patients, which is considered by some as better tool to assess obesity.

Last, number of subjects and ages in the study and control are not similar.

\section{Conclusions}

The current study demonstrated that after PVCs catheter ablation in structurally and functionally normal ventricles, the patients with MS had significantly higher acute and delayed recurrence rate of PVCs at follow up. Moreover, MS was an independent predictor of arrhythmia recurrence during the follow-up. MS and its proinflammatory status may represent a chronic irritative mechanism in these patients, leading to subclinical alterations that can affect catheter ablation outcomes, with an higher recurrence rate in PVCs mediated via inflammation.

\section{Competing interests}

The authors declare that they have no competing interests.

\section{Authors' contributions}

CS made conception and study design, acquisition, analysis and interpretation of data and wrote and reviewed the manuscript. SK performed the statistical analysis and reviewed the manuscript. VK has reviewed the manuscript critically. RM participated in study design and coordination, and has been involved in revising critically the manuscript and has given final approval of the version to be published. All authors read and approved the final manuscript version.

\section{Author details}

'Department of Medical, Surgical, Neurological, Metabolic and Geriatric Sciences, Second University of Naples, Naples, Italy. ${ }^{2}$ Cardiovascular Department and Electrophysiology Unit, Santa Maria Terni Hospital, Terni, Italy. ${ }^{3}$ Cardiology, KAT hospital, Athens, Greece. ${ }^{4} 1$ st Cardiology Department, AHEPA University Hospital, Thessaloniki, Greece. ${ }^{5}$ Department of Anesthesiological Surgical and Emergency Sciences II, University of Naples, Naples, Italy. ${ }^{6}$ Department of Plastic and Reconstructive Surgery, Second University of Naples, Naples, Italy. ${ }^{7}$ Columbia University Medical Center, New York, New York, USA. ${ }^{8}$ Current address: Piazza Miraglia, 2, Napoli 80138, Italy.

Received: 3 June 2014 Accepted: 15 September 2014

Published: 6 December 2014

\section{References}

1. Third report of the national cholesterol education program (NCEP) expert panel on detection, evaluation, and treatment of high blood cholesterol in adults (Adult Treatment Panel III). Final report. Circulation 2002, 106:3143-3421.

2. Ford ES: The metabolic syndrome and mortality from cardiovascular disease and all-causes: findings from the national health and nutrition examination survey II mortality study. Atherosclerosis 2004, 173:309-314.

3. Malik S, Wong ND, Franklin SS, Kamath TV, L'Italien GJ, Pio JR, Williams GR: Impact of the metabolic syndrome on mortality from coronary heart disease, cardiovascular disease, and all causes in United States adults. Circulation 2004, 110:1245-1250.

4. Alberti KG, Eckel RH, Grundy SM, Zimmet PZ, Cleeman Jl, Donato KA, Fruchart JC, James WP, Loria CM, Smith SC Jr, International Diabetes Federation Task Force on Epidemiology and Prevention: Harmonizing the metabolic syndrome: a joint interim statement of the international diabetes federation task force on epidemiology and prevention; national heart, lung, and blood institute; american heart association; world heart federation; international atherosclerosis society; and international association for the study of obesity. Circulation 2009, 120:1640-1645.

5. Ford ES: Risks for all-cause mortality, cardiovascular disease, and diabetes associated with the metabolic syndrome: a summary of the evidence. Diabetes Care 2005, 28:1769-1778.

6. Beltrán-Sánchez H, Harhay MO, Harhay MM, McElligott S: Prevalence and trends of metabolic syndrome in the adult U.S. population, 1999-2010. J Am Coll Cardiol 2013, 62:697-703.

7. Soydinc S, Davutoglu V, Akcay M: Uncomplicated metabolic syndrome is associated with prolonged electrocardiographic QTc interval and QTc dispersion. Ann Noninvasive Electrocardiol 2006, 11:313-317. 
8. Lee KT, Tang PW, Tsai WC, Liu IH, Yen HW: Differential effects of central and peripheral fat tissues on the delayed rectifier $\mathrm{K}(+)$ outward currents in cardiac myocytes. Cardiology 2013, 125:118-124.

9. Corbi GM, Carbone S, Ziccardi P, Giugliano G, Marfella R, Nappo F, Paolisso G, Esposito K, Giugliano D: FFAs and QT intervals in obese women with visceral adiposity: effects of sustained weight loss over 1 year. J Clin Endocrinol Metab 2002, 87:2080-2083.

10. Marfella R, De Angelis L, Nappo F, Manzella D, Siniscalchi M, Paolisso G, Giugliano D: Elevated plasma fatty acid concentrations prolong cardiac repolarization in healthy subjects. Am J Clin Nutr 2001, 73:27-30

11. Provotorov VM, Glukhovskii ML: Rhythm and conductivity disorders in patients at the initial stages of metabolic syndrome. Klin Med (Mosk) 2009, 87:26-28.

12. Provotorov VM, Glukhovskii ML: Ventricular extrasystole in patients with metabolic syndrome. Klin Med (Mosk) 2010, 88:29-31.

13. Gaita F, Giustetto C, Di Donna P, Richiardi E, Libero L, Brusin MC, Molinari G, Trevi G: Long-term follow-up of right ventricular monomorphic extrasystoles. J Am Coll Cardiol 2001, 38:364-370,

14. Lerman BB, Stein KM, Engelstein ED, Battleman DS, Lippman N, Bei D, Catanzaro D: Mechanism of repetitive monomorphic ventricular tachycardia. Circulation 1995, 92:421-429.

15. Dong M, Ren J: What fans the fire: insights into mechanisms of leptin in metabolic syndrome- associated heart diseases. Curr Pharm Des 2014, 20:652-658

16. European Heart Rhythm Association, Heart Rhythm Society, Zipes DP. Camm AJ, Borggrefe M, Buxton AE, Chaitman B, Fromer M, Gregoratos G, Klein G, Moss AJ, Myerburg RJ, Priori SG, Quinones MA, Roden DM, Silka MJ, Tracy C, Smith SC Jr, Jacobs AK, Adams CD, Antman EM, Anderson JL, Hunt SA, Halperin JL, Nishimura R, Ornato JP, Page RL, Riegel B, Priori SG, Blanc JJ, Budaj A, et al: ACC/AHA/ESC 2006 guidelines for management of patients with ventricular arrhythmias and the prevention of sudden cardiac death: a report of the American college of cardiology/American heart association task force and the European society of cardiology committee for practice Guidelines (Writing committee to develop guidelines for management of patients with ventricular arrhythmias and the prevention of sudden cardiac death). J Am Coll Cardiol 2006, 48:e247-e346.

17. Wijnmaalen AP, Delgado V, Schalij MJ, Van Taxis CF VH, Holman ER, Bax JJ, Zeppenfeld K: Beneficial effects of catheter ablation on left ventricular and right ventricular function in patients with frequent premature ventricular contractions and preserved ejection fraction. Heart 2010, 96:1275-1280

18. Ischiropoulos H: Biological tyrosine nitration: a pathophysiological function of nitric oxide and reactive oxygen species. Arch Biochem Biophys 1998, 356:1-11.

19. Alberti KG1, Zimmet P, Shaw J: Metabolic syndrome-a new world-wide definition. A consensus statement from the international diabetes federation. Diabet Med 2006, 23:469-480.

20. Duflou J, Virmani R, Rabin I, Burke A, Farb A, Smialek J: Sudden death as a result of heart disease in morbid obesity. Am Heart J 1995, 130:306-313.

21. Lalani AP, Kanna B, John J, Ferrick KJ, Huber MS, Shapiro LE: Abnormal signal-averaged electrocardiogram (SAECG) in obesity. Obes Res 2000, $8: 20-28$.

22. Huang H, Amin V, Gurin M, Wan E, Thorp E: Diet-induced obesity causes long QT and reduces transcription of voltage-gated potassium channels. J Mol Cell Cardiol 2013, 59:151-158.

23. Schunkert $\mathrm{H}$ : Obesity and target organ damage: the heart. Int I Obes Relat Metab Disord 2002, 26(Suppl 4):S15-S20

24. Grekin RJ, Vollmer AP, Sider RS: Pressor effects of portal venous oleateinfusion. A proposed mechanism for obesity hypertension. Hypertension 1995, 26:193-198.

25. Diaz-Melean CM, Somers VK, Rodriguez-Escudero JP, Singh P, Sochor O, Llano EM, Lopez-Jimenez F: Mechanisms of adverse cardiometabolic consequences of obesity. Curr Atheroscler Rep 2013, 15:364.

26. Endoh Y, Endoh I, Geczy C, Nakagomi A, Kusama Y: Inflammation and atrial fibrillation. J Arrhythmia 2011, 27:106-115.

27. Drolet B, Simard C, Gailis L, Daleau P: Ischemic, genetic and pharmacological origins of cardiac arrhythmias: the contribution of the Quebec heart institute. Can J Cardiol 2007, 23(Suppl B):15B-22B.

28. Jeong EM, Liu M, Sturdy M, Gao G, Varghese ST, Sovari AA, Dudley SC Jr: Metabolic stress, reactive oxygen species, and arrhythmia. J Mol Cell Cardiol 2012, 52:454-463.
29. Bharati S, Lev M: Cardiac conduction system involvement in sudden death of obese young people. Am Heart J 1995, 129:273-281.

30. Tandri H, Saranathan M, Rodriguez ER, Martinez C, Bomma C, Nasir K, Rosen B, Lima JA, Calkins H, Bluemke DA: Noninvasive detection of myocardial fibrosis in arrhythmogenic right ventricular cardiomyopathy using delayedenhancement magnetic resonance imaging. J Am Coll Cardiol 2005, 45:98-103.

31. Nazarian S, Bluemke DA, Halperin HR: Applications of cardiac magnetic resonance in electrophysiology. Circ Arrhythm Electrophysiol 2009, 2:63-71.

32. Globits S, Kreiner G, Frank H, Heinz G, Klaar U, Frey B, Gössinger H: Significance of morphological abnormalities detected by MRI in patients undergoing successful ablation of right ventricular outflow tract tachycardia. Circulation 1997, 96:2633-2640.

33. Ling Z, Liu Z, Su L, Zipunnikov V, Wu J, Du H, Woo K, Chen S, Zhong B, Lan $X$, Fan J, Xu Y, Chen W, Yin Y, Nazarian S, Zrenner B: Radiofrequency ablation vs. antiarrhythmic medication for treatment of ventricular premature beats from the right ventricular outflow tract: a prospective randomized study. Circ Arrhythm Electrophysiol 2014, 7:237-243.

34. Sporton S, Earley M, Nathan A, Schilling R: Electroanatomic versus fluoroscopic mapping for catheter ablation procedures: a prospective randomized study. J Cardiovasc Electrophysiol 2004, 15:310-315.

35. Shpun S, Gepstein L, Hayam G, Ben-Haim S: Guidance of radiofrequency endocardial ablation with real-time three-dimensional magnetic navigation system. Circulation 1997, 96:2016-2021.

36. Smeets J, Ben-Haim S, Rodriquez L, Timmermans C, Wellens H: New method for nonfluoroscopic endocardial mapping in humans. Accuracy assessment and first clinical results. Circulation 1998, 97:2426-2432.

37. Mohanty S, Mohanty P, Di Biase L, Bai R, Pump A, Santangeli P, Burkhardt D, Gallinghouse JG, Horton R, Sanchez JE, Bailey S, Zagrodzky J, Natale A: Impact of metabolic syndrome on procedural outcomes in patients with atrial fibrillation undergoing catheter ablation. J Am Coll Cardiol 2012, 59:1295-1301.

doi:10.1186/1471-2261-14-176

Cite this article as: Sardu et al:: Metabolic syndrome is associated with a poor outcome in patients affected by outflow tract premature ventricular contractions treated by catheter ablation. BMC Cardiovascular Disorders 2014 14:176.

\section{Submit your next manuscript to BioMed Central and take full advantage of:}

- Convenient online submission

- Thorough peer review

- No space constraints or color figure charges

- Immediate publication on acceptance

- Inclusion in PubMed, CAS, Scopus and Google Scholar

- Research which is freely available for redistribution 